\section{Nutritional quality, safety and sensory properties of smoked tench (Tinca tinca) pâté from Trasimeno Lake, Italy}

\author{
Raffaella Branciari, ${ }^{1}$ Rossana Roila, ${ }^{1}$ \\ Andrea Valiani, ${ }^{2}$ David Ranucci, ${ }^{1}$ \\ Roberta Ortenzi, ${ }^{2}$ Dino Miraglia, ${ }^{1}$ \\ Lucia Bailetti, ${ }^{3}$ Raffaella Franceschini ${ }^{4}$ \\ ${ }^{1}$ Department of Veterinary Medicine, \\ University of Perugia; ${ }^{2}$ Istituto \\ Zooprofilattico Sperimentale \\ dell'Umbria e delle Marche, "Togo \\ Rosati", Perugia; ${ }^{3}$ Italian Center of \\ Sensory Analysis \& Innovation - CIAS \\ Innovation, Macerata; ${ }^{4}$ Department of \\ Sustainability Engineering, Guglielmo \\ Marconi University, Rome, Italy
}

\begin{abstract}
The present study evaluated the safety, nutritional and sensory properties of fish pâtés made from smoked tench (Tinca tinca) pulp. Two formulations of tench pâté were produced, one of which included olive oil and the other contained mascarpone cheese. The prepared pâté jars were thermally treated according to the method applied in the canning industry. The inactivation of Clostridium botulinum during thermal treatment was determined through a challenge test study, demonstrating the complete depletion of targeted bacteria. Tench pâtés showed high nutritional properties, especially the formulation with olive oil, which was characterised by lower contents of cholesterol and saturated fatty acids and a high level of monounsaturated fatty acids. The two experimental formulations possessed a specific sensory profile, due to the ingredients incorporated into the products. Consumers' evaluation established differences in the acceptance of the two products: the formulation with added olive oil was more appreciated by consumers, who displayed a higher purchase intent for this product. The study suggests that minced smoked tench is not only a promising ingredient for pâté production but that it also represents a value-added product able to contribute to freshwater food consumption.
\end{abstract}

\section{Introduction}

Fish in the human diet is considered as an important source of nutrients of high biological value with a range of health benefits
(Özogul et al., 2007; Branciari et al., 2017a). Many freshwater fish species have not yet been utilised effectively because of various reasons, including bony flesh, characteristic flavour and odour, small size, unacceptable textural properties and other factors. However, the utilisation of such fish species would be desirable for their valuable nutritional properties (Steffens, 1997; Vasconi et al., 2015). A strategy to increase the consumption of freshwater fish is by pre-processing the fish (Venugopal et al., 1995). This approach is in line with consumers' demand towards safe, user-friendly and high in nutritional value products and with the strong attitude in consuming locally-sourced products, both typical and innovative (de Quadros et al., 2015; Branciari et al., 2016a; Branciari et al., 2017a). Smoking of fish is an ancient preservation method, and it has economic importance for the seafood market (Özogul et al., 2010). In the Umbria region (Italy), smoked tench (Tinca tinca) an autochthonous fish species of Trasimeno Lake is an artisanal fish product (Natali, 2002) prepared by a small fishery consortium along Trasimeno Lake. This economically important fish product has emerged in numerous markets. Due to the increasing consumers' demand for fish foods with prolonged shelf-life, the consortium started to process the smoked tench in ready-to-eat (RTE) pâté. As a cooked RTE product, pâté has greatly appreciated sensory characteristics and is popular in the gastronomy of many countries. Pâtés are traditionally prepared with goose "foie-gras" or pork liver. Nevertheless, fish-based pâtés are present in today's market mainly due to their nutritional benefits, offering a great variety of products with unique sensory characteristics (Lobo et al., 2015; Minozzo et al., 2004). The objective of this study was to use smoked tench from Trasimeno Lake, for the preparation of two pâtés' formulations and to assess their safety, nutritional value, sensory properties and consumers acceptability.

\section{Materials and Methods}

\section{Fish meat pastes preparation}

Smoked tench (T. tinca) was obtained, as reported by Branciari et al. (2016a). Briefly, tench was prepared by gutting, salting in brine $\left(22 \%\right.$ salt) at $10{ }^{\circ} \mathrm{C}$ for $2 \mathrm{~h}$, washing to remove the brine, hanging from a support at $0-4{ }^{\circ} \mathrm{C}$ for $16-24 \mathrm{~h}$ and, finally, smoking in a convection smoking oven (inner final temperature around $72^{\circ} \mathrm{C}$ ) for 6 h. The smoked tench pulp was minced and trimmed in order to prepare tench pâté in
Correspondence: Raffaella Branciari, Dipartimento di Medicina Veterinaria, Università degli Studi di Perugia, Via San Costanzo 4, 06126 Perugia (PG), Italy. Tel.: +39.075.5857932 - Fax: +39.075.5857932. E-mail: raffaella.branciari@unipg.it

Key words: Challenge test study, Fish pâté, Nutritional declaration, Consumer preference.

Acknowledgements: The authors want to thanks Fausto Canalicchio for his technical assistance and Cooperativa dei Pescatori del Lago Trasimeno for providing technical support and advice in formulating experimental fish pâté.

Conflict of interest: the authors declare no potential conflict of interest

Funding: support for this research was provided by Umbria Region, PSR, Mis. 1.2.4. Il Paté Omega 3 del Trasimeno Buono e Sicuro.

Received for publication: 21 February 2019.

Revision received: 10 July 2019.

Accepted for publication: 11 July 2019.

This work is licensed under a Creative Commons Attribution-NonCommercial 4.0 International License (CC BY-NC 4.0).

(C) Copyright: the Author(s), 2019

Licensee PAGEPress, Italy

Italian Journal of Food Safety 2019; 8:8130 doi:10.4081/ijfs.2019.8130

two different experimental formulations: one with olive oil (O-TP) and the other one with mascarpone cheese (M-TP). In the OTP recipe, the minced fish meat was mixed with olive oil $(41.1 \%)$, parsley $(1.65 \%)$ and lemon juice $(1.65 \%)$. In M-TP, the minced fish meat was mixed with mascarpone cheese $(42.55 \%)$, cream $(12.77 \%)$, parsley $(1.28 \%)$ and lemon juice $(0.85 \%)$. One hundred and fifty grams of the mix pâté was placed in a jar (212-mL volume) and transferred to the autoclave (Frigojollinox Stery 50, Frigojollinox, Campobasso, Italy). Three batches of 90 jars were produced for the experiment. In order to ensure the product's safety, the steriliser was set in accordance to the standard thermal treatment parameters used in the canning industry: $121.1^{\circ} \mathrm{C}$ for $12 \mathrm{~s}$ (Diao et al., 2014; Margosch et al., 2006).

Evaluation of Clostridium botulinum inactivation during thermal treatment

In order to define the time-temperature profile, the internal temperature of the samples was recorded by eight miniature, selfcontained, computer downloadable elec- 
tronic data loggers (Thermo Button 22T, Proges-Plus, Willems, France) inserted into eight separate fish pâté jars (four O-TP and four M-TP). The above-mentioned jars were placed randomly at different points inside the steriliser, namely, near the centre, and close to the top, bottom and sides of the steriliser (Figure 1) as reported by other authors (Giannakourou et al., 2005; Jedermann et al., 2009). The procedure was performed for each batch, for the evaluation of three sterilisation cycles. Temperatures recorded by data loggers were downloaded using the Thermotrack software (Plug and Track, Proges-Plus).

For calculating the thermal inactivation (death) kinetics, a $D_{120^{-}}$value of $0.48 \mathrm{~min}$, and a $z$-value of $10.2^{\circ} \mathrm{C}$ were applied, as reported for $C$. botulinum proteolytic types ABF, by van Asselt and Zwietering (2006). Data from data loggers were analysed by the software of the Food Safety and Inspection Service of the United States Department of Agriculture (www.fsis.usda.gov) to evaluate the worstcase scenario for the process.

Microbiological challenge tests play an important role in the validation of processes that are intended to deliver some degree of lethality against a target organism and in the verification of compliance with the predetermined performance standard (US FDA, 2001). For canned food, it is appropriate to conduct inoculated studies as part of the protocol for process validation (US FDA, 2001). Hence, to validate the fish pastes production process and ensure the safety of the products, the efficacy of thermal treatment on $C$. botulinum was evaluated by a specific challenge test detailed in the Guidelines for Safe Practices for Food Processes published by the US Food and Drug Administration (US FDA, 2001). The experimental design involved the production of three batches for each of the two fish pâté recipes. Each batch included three experimental groups of six samples each. The first experimental group (CONTAM) consisted of fish pâté experimentally inoculated with spores of $C$. botulinum (approximately $10^{5} \mathrm{spores} / \mathrm{g}$ ). These samples units were used to assess the efficacy of thermal treatment on $C$. botulinum. For the second group (CTR), the suspension used in the CONTAM group was replaced by the same volume of sterile saline solution. In the CTR group, physical and chemical analyses were conducted to verify that the addition of a defined amount of liquid to the original formulation does not affect the product. The third experimental group (BLANK) was produced by strictly following the producer's recipe, to compare the products submitted to challenge testing with the products that are routinely manufactured by the producer and to evaluate the physical-chemical characteristics of fish pâté. These BLANK samples were also used to exclude contamination by $C$. botulinum occurring naturally in this type of product.

A non-toxigenic strain of C. botulinum (C. botulinum-like type B, CL14NT), provided by the Italian Centro Nazionale di Riferimento per il Botulismo, was used in the challenge test. The strain was revitalised in tryptone-peptone-glucose-yeast broth (Biokar Diagnostics, Pantin Cedex, France) incubated at $30 \pm 1^{\circ} \mathrm{C}$ for 4 days. The bacterial suspension was then stored at $4 \pm 1^{\circ} \mathrm{C}$ under aerobic conditions for 10 days until 95\% sporulation was observed by microscopic examination. In order to eliminate all the vegetative cells, the spore suspension was heated at $75^{\circ} \mathrm{C}$ for 15 min (Dutra et al., 2016). Subsequently, the suspension was centrifuged ( $1800 \mathrm{rpm}, 4^{\circ} \mathrm{C}$ for $\left.1 \mathrm{~h}\right)$ and the pellet re-suspended in $10 \mathrm{~mL}$ of sterile saline water. For spore enumeration by the standard UNI EN ISO 7218:2007 method, serial decimal dilutions in $0.1 \%$ peptone solution of the suspension were performed. Each dilution was then inoculated $(0.1 \mathrm{~mL})$ onto egg yolk agar (EYA) culture media plates (Biokar Diagnostics) and incubated at $37 \pm 1^{\circ} \mathrm{C}$ for $48 \pm 3 \mathrm{~h}$ under anaerobic conditions (detection limit $10 \mathrm{CFU} / \mathrm{g}$ ). The spore mixture was stored at $4 \pm 1^{\circ} \mathrm{C}$ until used, as reported by Reddy et al. (2010). The contamination of pâté was performed in an experimental plant. For this, the inoculums were added to the fish paste mass $(1.5 \mathrm{~kg})$, homogenised and then poured into glass jars. Clostridium botulinum was enumerated on BLANK samples $(3$ jars) before the heat treatment and on CONTAM sample units before (3 jars) and after ( 3 jars) the thermal treatment, by growth on EYA, as mentioned above.

In BLANK and CTR samples, the water activity $\left(\mathrm{a}_{\mathrm{w}}\right), \mathrm{pH}$ and $\mathrm{NaCl}$ analysis were achieved on three samples units for each batch. The $\mathrm{pH}$ measurements were carried out using a puncture electrode probe connected to a portable $\mathrm{pH}$ meter (Crison pH25, Crison Instruments, S.A., Barcelona, Spain). The salt content was determined by adopting the Volhard method (AOAC, 2000), and the $\mathrm{a}_{\mathrm{w}}$ was measured in according to Pecorelli et al., (2018) using an AquaLab Series 3 TE device (Decagon Devices, Inc., Pullman, WA, USA).

\section{Determination of nutritional decla- ration}

In order to define the nutritional declaration of fish pâtés, O-TP, M-TP and smoked tench, the moisture, ash and total nitrogen $(\mathrm{N})$ were measured (AOAC 2000), and the fatty acid profile (Branciari et al., 2014), fat and sugar contents (Ranucci et al., 2018), were determined, as detailed in the indicated references. Ten samples were analysed in triplicate. The protein content was calculated by multiplying the total $\mathrm{N}$ by a factor of 6.25 . Total cholesterol of each

Table 1. Physical-chemical characteristics of BLANK and CTR samples of both experimental recipes (O-TP and M-TP)(mean \pm standard deviation).

\begin{tabular}{|c|c|c|c|c|c|}
\hline & & Batch 1 & Batch 2 & Batch 3 & Mean value \\
\hline BLANK O-TP & $\begin{array}{l}\mathrm{a}_{\mathrm{w}} \\
\mathrm{pH} \\
\mathrm{NaCl}(\%)\end{array}$ & $\begin{array}{c}0.968 \pm 0.001 \\
5.72 \pm 0.02 \\
0.32 \pm 0.03\end{array}$ & $\begin{array}{c}0.971 \pm 0.001 \\
5.73 \pm 0.02 \\
0.37 \pm 0.02\end{array}$ & $\begin{array}{c}0.978 \pm 0.003 \\
5.79 \pm 0.02 \\
0.31 \pm 0.03\end{array}$ & $\begin{array}{c}0.972 \pm 0.005 \\
5.75 \pm 0.03 \\
0.33 \pm 0.03\end{array}$ \\
\hline CTR 0-TP & $\begin{array}{l}\mathrm{aw} \\
\mathrm{pH} \\
\mathrm{NaCl}(\%)\end{array}$ & $\begin{array}{c}0.969 \pm 0.001 \\
5.73 \pm 0.01 \\
0.30 \pm 0.05\end{array}$ & $\begin{array}{c}0.970 \pm 0.001 \\
5.72 \pm 0.01 \\
0.37 \pm 0.03\end{array}$ & $\begin{array}{c}0.977 \pm 0.001 \\
5.81 \pm 0.01 \\
0.32 \pm 0.02\end{array}$ & $\begin{array}{c}0.972 \pm 0.004 \\
5.75 \pm 0.04 \\
0.33 \pm 0.04\end{array}$ \\
\hline BLANK M-TP & $\begin{array}{l}\mathrm{a}_{\mathrm{w}} \\
\mathrm{pH} \\
\mathrm{NaCl}(\%)\end{array}$ & $\begin{array}{c}0.984 \pm 0.003 \\
5.62 \pm 0.02 \\
0.18 \pm 0.03\end{array}$ & $\begin{array}{c}0.982 \pm 0.001 \\
5.62 \pm 0.03 \\
0.20 \pm 0.03\end{array}$ & $\begin{array}{c}0.984 \pm 0.001 \\
5.66 \pm 0.03 \\
0.21 \pm 0.03\end{array}$ & $\begin{array}{c}0.983 \pm 0.002 \\
5.63 \pm 0.03 \\
0.20 \pm 0.03\end{array}$ \\
\hline CTR M-TP & $\begin{array}{l}\mathrm{a}_{\mathrm{w}} \\
\mathrm{pH} \\
\mathrm{NaCl}(\%)\end{array}$ & $\begin{array}{c}0.984 \pm 0.001 \\
5.64 \pm 0.04 \\
0.19 \pm 0.04\end{array}$ & $\begin{array}{c}0.982 \pm 0.001 \\
5.67 \pm 0.03 \\
0.21 \pm 0.02\end{array}$ & $\begin{array}{c}0.981 \pm 0.002 \\
5.63 \pm 0.01 \\
0.22 \pm 0.04\end{array}$ & $\begin{array}{c}0.983 \pm 0.002 \\
5.65 \pm 0.03 \\
0.21 \pm 0.03\end{array}$ \\
\hline
\end{tabular}


pâté was assayed using a commercial kit (Cat. number 10139050035: Biopharm, Darmstadt, Germany) and absorbance reading at $405 \mathrm{~nm}$ (Ultrospec 2011 Pro spectrophotometer, Amersham Pharmacia Biotech, Milan, Italy).

\section{Sensory analysis of pâté}

A descriptive sensory analysis was performed on O-TP, M-TP and a commercial tuna pâté (CP) using an eight-member panel, which was trained and selected based on the ISO 8586-1:1993 and ISO 85862:2008 criteria. The attributes were generated in pre-testing sessions, and the descriptive analysis of the pâté was replicated three times (Branciari et al., 2014). For quantification of the intensity of each attribute, the judges evaluated the sample in a monadic sequential manner, scoring the attributes on an unstructured 100-point scale, where 0 is the minimum intensity, and 100 is the maximum intensity, for each parameter. Fifteen attributes were assessed, according to ISO 13299:2003, comparing the two experimental pâtés (O-TP and M-TP) with CP. The assessors tasted samples coded with threedigit random numbers and served at room temperature.

\section{Consumer analysis}

Consumer tests were performed at the Fisheries Consortium of the Lake Trasimeno. Before testing, all consumers completed a questionnaire that included information regarding their age, sex, and the frequency of consumption of freshwater fish products (regular consumers were considered those who reported consuming fish at least once every 2 weeks). In total, 110 regular fish consumers (aged 20-60 years, 60 females and 50 males) were used for consumer evaluation. The pâté was served, using bread as a carrier. Practicing sessions were conducted before the test to allow consumers to become familiar with the use of a hedonic scale and to explain the meaning of the examined attributes (Branciari et al., 2016b). Samples were monadically served on white plastic plates identified by random three-digit codes. Consumers were asked to rate sensory attributes using a 9-point hedonic scale (from 1, "dislike extremely" to 9, "like extremely") for overall appearance, odour, taste, overall texture and overall liking. Purchase intent were evaluated using the binomial (yes/no) scale (Branciari et al., 2017b).

\section{Results and Discussion}

Among the time-temperature profiles belonging to both recipes and analysed using the software provided by the USDA, the most unfavourable was considered and is shown in Figure 2. The software reported that the non-isothermal profile applied to tench pâtés is equivalent to an isothermal treatment at $120^{\circ} \mathrm{C}$ for $6.869 \mathrm{~min}$ (Figure $3)$, thereby generating a $14.31 \mathrm{log}$ reduction

for $C$. botulinum. The results confirm that the heating treatment complies with the 12D concept ("botulinum cook") widely employed in the canned food industries, according to which, a 12-log cycle reduction in the numbers of $C$. botulinum is considered safe for ambient stored canned food

Table 2. Nutritional declaration of smoked tench pâtés, O-TP and M-TP.

\begin{tabular}{lccl} 
& Smoked tench* & 0-TP & M-TP \\
Energy value (kcal) & 133 & 447 & 277 \\
Energy value (kJ) & 556 & 1869 & 1160 \\
\hline Carbohydrates (\%) & 0.38 & 0.18 & 0.53 \\
Total sugars (\%) & 0.34 & 0.13 & 0.08 \\
\hline Fat (\%) & 4.69 & 44.15 & 25.90 \\
Saturated fatty acids (\%) & 13.67 & 27.33 & 64.78 \\
\hline Protein (\%) & 22.71 & 12.17 & 10.53 \\
Moisture (\%) & 69.96 & 41.85 & 59.76 \\
\hline Cholesterol (mg/100 g) & 90.00 & 61.83 & 110.64 \\
Ash (\%) & 2.67 & 2.04 & 3.28 \\
\hline Salt (\%) & 0.56 & 0.33 & 0.21 \\
\hline
\end{tabular}

*Smoked tench stored at $4^{\circ} \mathrm{C}$ under vacuum.

Table 3. Sensory profile of tench pâté with olive oil (O-TP) and tench pâté with mascarpone cheese (M-TP) compared with commercial pâté (CP).

\begin{tabular}{lcccccccc}
\hline Attributes & 0-TP & M-TP & CP & F & P & P $<0.05$ & P $<0.01$ & P $<0.001$ \\
Fresh vegetable odour & $70.59 \mathrm{c}$ & $27.55 \mathrm{a}$ & $14.10 \mathrm{~b}$ & 156.48 & 0.00 & 7.16 & 9.93 & 13.81 \\
Smoked odour & $32.49 \mathrm{a}$ & $58.31 \mathrm{~b}$ & $40.22 \mathrm{a}$ & 27.13 & 0.00 & 7.72 & 10.71 & 14.89 \\
\hline Butter odour & $28.70 \mathrm{a}$ & $73.36 \mathrm{c}$ & $51.59 \mathrm{~b}$ & 56.58 & 0.00 & 9.01 & 12.50 & 17.38 \\
Salt & $54.41 \mathrm{a}$ & $55.18 \mathrm{a}$ & $76.96 \mathrm{~b}$ & 18.70 & 0.00 & 8.98 & 12.46 & 17.33 \\
\hline Sweet & $36.06 \mathrm{a}$ & $67.38 \mathrm{~b}$ & $29.18 \mathrm{a}$ & 41.54 & 0.00 & 9.58 & 13.30 & 18.50 \\
Bitter & $20.16 \mathrm{a}$ & $16.58 \mathrm{a}$ & $59.02 \mathrm{~b}$ & 34.12 & 0.00 & 12.22 & 16.97 & 23.59 \\
\hline Acid & $20.77 \mathrm{a}$ & $53.77 \mathrm{~b}$ & $39.00 \mathrm{ab}$ & 31.42 & 0.00 & 8.94 & 12.41 & 17.26 \\
Graininess & $72.08 \mathrm{c}$ & $63.62 \mathrm{~b}$ & $8.43 \mathrm{a}$ & 333.20 & 0.00 & 5.74 & 7.97 & 11.09 \\
\hline Cohesiveness & $39.83 \mathrm{a}$ & $48.92 \mathrm{a}$ & $67.66 \mathrm{~b}$ & 19.82 & 0.00 & 9.67 & 13.42 & 18.66 \\
Fresh vegetable flavour & $71.93 \mathrm{c}$ & $33.63 \mathrm{~b}$ & $18.79 \mathrm{a}$ & 117.74 & 0.00 & 7.66 & 10.64 & 14.79 \\
\hline Smoked flavour & $43.06 \mathrm{a}$ & $60.98 \mathrm{~b}$ & $41.96 \mathrm{a}$ & 6.51 & 0.01 & 12.70 & 17.62 & 24.51 \\
Butter flavour & $29.93 \mathrm{a}$ & $71.31 \mathrm{c}$ & $43.65 \mathrm{~b}$ & 39.16 & 0.00 & 10.22 & 14.18 & 19.72 \\
\hline Mouth coating & 76.74 & 69.52 & 78.09 & 1.34 & 0.29 & 12.05 & 16.73 & 23.26 \\
Persistence of bitter taste & $40.75 \mathrm{~b}$ & $10.77 \mathrm{a}$ & $63.77 \mathrm{c}$ & 68.40 & 0.00 & 9.74 & 13.51 & 18.79 \\
\hline Persistence of salty taste & $36.05 \mathrm{a}$ & $26.45 \mathrm{a}$ & $68.96 \mathrm{~b}$ & 61.11 & 0.00 & 8.65 & 12.01 & 16.70 \\
\hline
\end{tabular}

a, b, c: within each attribute, different lowercase letters indicate differences between pâté recipes

Table 4. Mean scores assigned by consumers for sensory acceptability and purchase intent of fish pâtés.

\begin{tabular}{lcccc} 
Attribute & O-TP & M-TP & CP & P-value \\
Overall appearance & $7.41 \pm 1.19 \mathrm{~b}$ & $7.51 \pm 1.11 \mathrm{~b}$ & $6.82 \pm 0.95 \mathrm{a}$ & $<0.001$ \\
Odour & $7.49 \pm 1.04 \mathrm{~b}$ & $7.28 \pm 1.23 \mathrm{~b}$ & $6.41 \pm 1.27 \mathrm{a}$ & $<0.001$ \\
\hline Taste & $7.90 \pm 1.20 \mathrm{c}$ & $7.19 \pm 1.54 \mathrm{~b}$ & $6.15 \pm 1.52 \mathrm{a}$ & $<0.001$ \\
Texture & $7.72 \pm 1.01$ & $7.39 \pm 1.22$ & $7.32 \pm 0.97$ & 0.070 \\
\hline Overall liking & $7.77 \pm 1.20 \mathrm{c}$ & $7.22 \pm 1.50 \mathrm{~b}$ & $6.29 \pm 1.37 \mathrm{a}$ & $<0.001$ \\
Positive ("yes") purchase intent (\%) & $78.26 \%$ & $69.57 \%$ & $55.07 \%$ \\
\hline
\end{tabular}

Mean \pm standard deviation, based on 68 consumers and a 9-point hedonic scale $(1=$ dislike extremely; $5=$ neither like nor dislike; $9=$ like extremely). Means within the same row followed by different letters are significantly different $(\mathrm{P}<0.05)$. 
products (Lindström et al., 2006; Silva and Gibbs, 2010).

The enumeration of $C$. botulinum performed on BLANK samples before the thermal treatment showed the absence of natural contamination of the product $(C$. botulinum $<10 \mathrm{CFU} / \mathrm{g}$ ). The contamination level of CONTAM samples before the thermal treatment was approximately $5 \log$ of C. botulinum in each pâté recipe $(5.43 \pm$ $0.31 \log \mathrm{CFU} / \mathrm{g}$ in O-TP; $5.63 \pm 0.37 \mathrm{log}$ $\mathrm{CFU} / \mathrm{g}$ in $\mathrm{M}-\mathrm{TP})$. After the thermal treatment, the $C$. botulinum spores were inactivated to below the detection limit $(<10$ $\mathrm{CFU} / \mathrm{g}$ ). The reported results confirm that the employed production process complied with the pre-determined performance standard (12D concept). In particular, the applied thermal treatment delivers an appropriate degree of lethality against the target organism, and it is suited to ensure the safety of the products. The heat-treated product was approved for human consumption and sensory evaluation, as it did not show evidence of leakage or swelling, a defect of heat-treated fish paste (Lobo et al., 2015).

The physicochemical characteristics of the BLANK and CTR samples are reported in Table 1, for O-TP and M-TP, respectively. No difference in $\mathrm{pH}, \mathrm{a}_{\mathrm{w}}$ or $\mathrm{NaCl}$ was detected among the batches, between the two different sample units (BLANK and CTR). Knowledge of the physical-chemical properties is necessary for the correct execution of the challenge test in order to compare the products submitted to challenge testing with those routinely manufactured by the processor (Berefourt et al., 2011).

Tench pâté is a product of considerable nutritional value, mainly due to its high protein content. Although lower than that of tench pulp $(22.71 \%)$, the protein level of tench pâté is considerably high when compared with the data for other fish pastes (Lobo et al., 2015; Minozzo et al., 2004). It was not surprising to find the two pâtés possessed limited carbohydrate contents, as it is known that fish have low amounts of carbohydrate (Tocher, 2003). The smoked tench contained about $5 \%$ lipid, and the addition of the oil and mascarpone to the experimental recipes increased the level, as shown in Table 2. Differences in lipid profile were recorded among the two formulations, as the M-TP contained a lower percentage of fat, but a higher level of saturated fatty acids (SFA), due to the presence of mascarpone in the formulations. Even though OTP is characterised by a higher level of fat than M-TP, this is constituted mainly by monounsaturated fatty acids (MUFA) $(77.55 \%)$ because the presence of olive oil in the recipe limited the increase of SFA, as olive oil is high in MUFA, with a considerable amount of oleic acid $\left(\mathrm{C} 18: 1 \Delta^{9 \mathrm{c}}\right)$ (Visioli and Galli, 1998). This aspect is of utmost importance, considering that a diet rich in MUFA containing oleic acid from virgin olive oil has been found to have beneficial effects in the prevention of cardiovascular disease (Visioli and Galli, 1998; Schwingshackl and Hoffmann, 2014). The oleic acid is responsible for the reduction of plasmatic cholesterol levels and the improvement of the low-density lipoprotein/high-density lipoprotein ratio.

The European Food Safety Authority (EFSA, 2011) recommends the replacement of SFA with an equal amount of MUFA in order to reduce blood low-density lipoprotein and cholesterol levels. Cholesterol content varied among the two formulations. The literature states that this value can vary in freshwater fish, especially tench, depending on the age and harvest season (Kopicova and Vavreinova, 2007). The

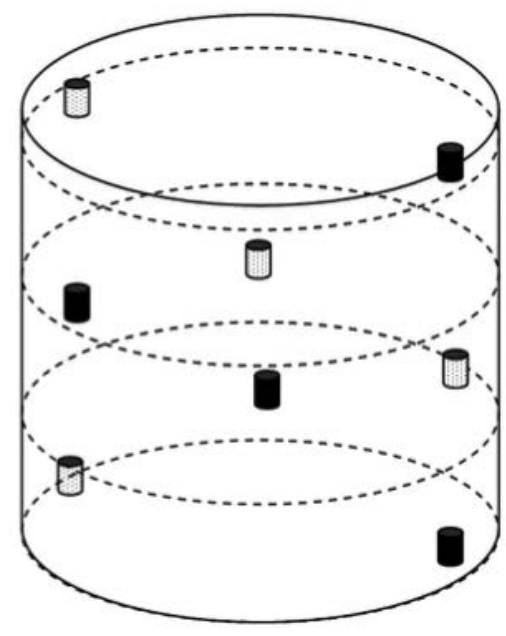

Figure 1. Measuring points of the data $\log$ gers inside the steriliser (the shaded and black loggers correspond to different fish pâté recipes; the dotted lines defines the steriliser's layers).

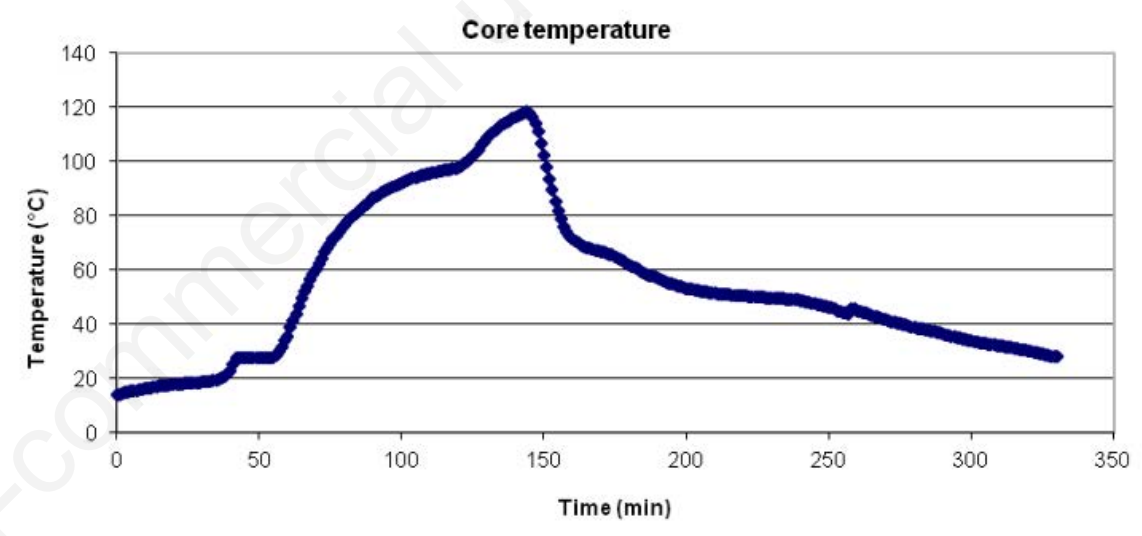

Figure 2. Most unfavourable thermal profile logged during the thermal treatment.

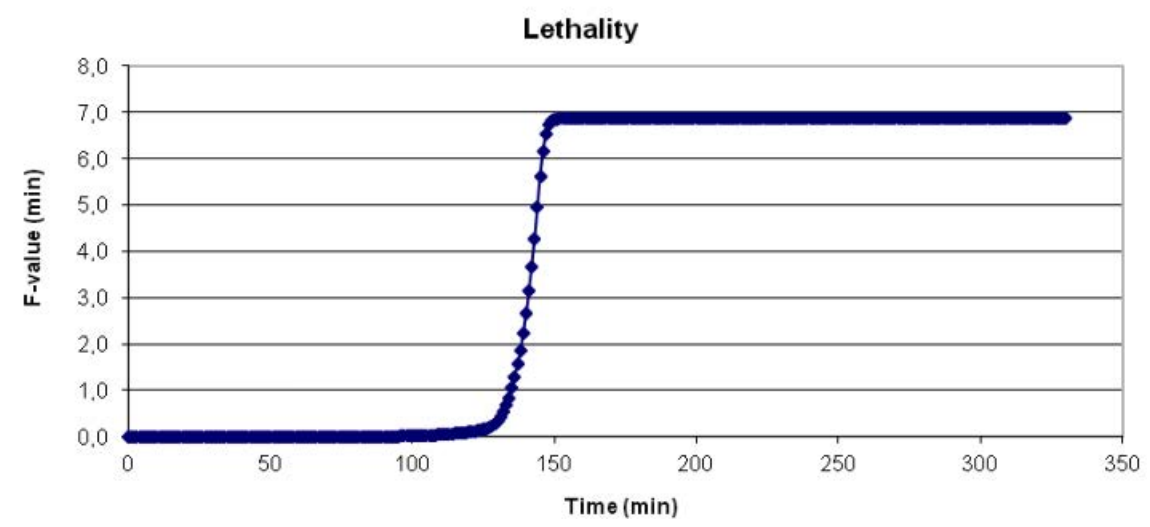

Figure 3. Inactivation of Clostridium botulinum according to the thermal treatment time. 
amount of cholesterol was lower in O-TP than M-TP, reflecting the amount in smoked tench and the presence of olive oil in the pâtés. On the contrary, the addition of mascarpone to the M-TP recipe enhanced the cholesterol level in M-TP. While a moderate level of salt $(\mathrm{NaCl})$ was present in all samples, these formulations are in line with current consumers habits and the food industry's approach to promote health and prevent diseases, by limiting certain nutrients in the diet (Kloss et al., 2015).

The descriptive analysis revealed higher intensity of the fresh vegetable attribute in O-TP. The flavour associated with freshwater fish is usually mild, and most fish have a common sweet and plant-like aroma (Turchini et al., 2004). This sensory attribute was exalted in O-TP, in which the addition of olive oil and parsley contributed to the vegetable-like flavour (Table 3). This intense aromatic note of oil and parsley diminished the perception of aromatic molecules associated with the smoking process of the tench, resulting in a lower intensity of the smoked attribute in O-TP than M-TP (considering the same degree of smoking of the starting material). The more intense lactic/butter and smoked attributes in M-TP than O-TP characterised the aromatic profile of the M-TP product, which also presented more intense sweet and sour tastes, attributable to the taste profile of mascarpone and cream. The CP had heightened and more persistent bitter and salty flavours and the consistency was characterised by a higher adhesiveness and a lower graininess than the two experimental formulations (O-TP and M-TP). The greater saltiness derived from the relatively higher salt content in $\mathrm{CP}$.

In addition, Tench flesh is characterized by a considerable amount of bone therefore a grainy perception could be a consequence of milder mincing process than CPs (Shaviklo et al., 2010). Furthermore, chopped parsley and the physical state of the carrier (olive oil) may contribute to the grainy perception of $\mathrm{M}-\mathrm{TP}$ and even more of O-TP.

The consumer acceptance data (Table 4) highlighted differences in the examined attributes and consumer acceptability among the groups. O-TP received the highest scores for taste and overall liking while $\mathrm{CP}$ received the lowest score for overall appearance, odour, taste and overall liking. Differences in the acceptance of the appearance were found, probably because the experimental tench pâtés showed a more artisanal appearance, usually more appreciated by consumers that usually eat this product (Di Monaco et al., 2009).

Species, such as tench, could present a muddy/hearty odour and flavour, owing to their ecological habits. This off-flavour is mainly caused by two isoprene compounds, geosmin and 2-methylisoborneol, usually found in pond bottom soil, which is the major feed intake of this species (Papp et al., 2007; Varga et al., 2015). Nevertheless, the process and the ingredients in both recipes removed the possibility of the presence of this off-flavour, and, consequently, both formulated pâtés were more appreciated than CP. Despite the graininess in the formulated pâtés perceived by the panel and confirmed by the consumers, no difference in the texture acceptability among the three formulations was recorded, probably because the two carriers (olive oil and mascarpone) made the perception of the grain more pleasant.

For the evaluation of purchase intent, consumers would prefer O-TP (affirmative purchase intent of $78.3 \%$ ) over M-TP $(46.3 \%)$ and CP (44.4\%). The overall liking and taste $(P<0.05)$ were significantly important in determining the higher purchase intent of O-TP and M-TP versus CP, especially O-TP.

The two tench pâté recipes prepared in this study proved to be safe products for human consumption, with significant nutritional values and sensory acceptance, especially O-TP. Therefore, considering the current consumers' preferences directed toward fast-food consumption, the developed pâtés can be regarded as a time-saving strategy, more easily incorporable into busy lifestyles compared with homemade food (van der Horst et al., 2011). The study findings also reveal that there is great potential in the consumption of tench pâté as an alternative freshwater food product of high value.

\section{References}

AOAC, 2000. Official Method of Analysis. 17th ed. Association of Official Analytical Chemists Inc., Arlington, VA, USA.

Beaufort A, 2011. The determination of ready-to-eat foods into Listeria monocytogenes growth and no growth categories by challenge tests. Food Control 22:1498-1502.

Branciari R, Mughetti L, Ranucci D, Miraglia D, Valiani A, Acuti G, Selvaggini R, Trabalza Marinucci M, 2014. Influence of manufacturing procedure on the compositional and sensory properties of n-3 fatty acid enriched Pecorino cheese. J Dairy Res 29:1-7.

Branciari R, Ranucci D, Urbani E, Valiani
A, Trabalza-Marinucci M, Dal Bosco A, Franceschini R, 2017a. Freshwater fish burgers made from four different fish species as a valuable strategy appreciated by consumers for introducing EPA and DHA into a human diet. J Aquat Food Prod T 26:686-94.

Branciari R, Galarini R, Giusepponi D, Trabalza-Marinucci M, Forte C, Roila R, Miraglia D, Servili M, Acuti G, Valiani A, 2017b. Oxidative status and presence of bioactive compounds in meat from chickens fed polyphenols extracted from olive oil industry waste. Sustainability 9:1566.

Branciari R, Valiani A, Franceschini R, Ranucci D, Lupattelli A, Urbani E, Ortenzi R, 2016a. Thermal inactivation and growth potential of Listeria monocytogenes in smoked tench. Ital J Food Saf 5:168-72.

Branciari R, Balzano M, Pacetti D, Trabalza-Marinucci M, Della Casa G, Miraglia D, Capotorti A, Frega NG, Ranucci D, 2016b. Dietary CLA supplementation of pigs confers higher oxidative stability to Ciauscolo and Fabriano salami produced from their meat with no negative impact on the physicochemical, microbiological and sensorial characteristics. Eur J Lipid Sci Technol 118:1475-85.

de Quadros DA, de Oliveira Rocha IF, Ferreira SMR, Bolini HMA, 2015. Low-sodium fish burgers: Sensory profile and drivers of liking. LWT Food Sci Technol 63:236-42.

Di Monaco R, Cavella S, Masi P, Sevi A, Caroprese M, Marzano A, Conte A, Del Nobile MA, 2009. Blue fish burgers: nutritional characterisation and sensory optimisation. Int $\mathrm{J}$ Food Sci Technol 44:1634-41.

Diao MM, André S, Membré JM, 2014. Meta-analysis of D-values of proteolytic Clostridium botulinum and its surrogate strain Clostridium sporogenes PA 3679. Int J Food Microbiol 174:23-30.

Dutra MP, de Cássia Aleixo G, Ramos ADLS, Silva MHL, Pereira MT, Piccoli RH, Ramos EM, 2016. Use of gamma radiation on control of Clostridium botulinum in mortadella formulated with different nitrite levels. Radiat Phys Chem 119:125-9.

EFSA, 2011. Scientific Opinion on the substantiation of health claims related tooleic acidintended toreplace saturated fatty acids (SFAs) in foods or diets and maintenance of normal blood LDL-cholesterol concentrations (ID673, 728, $729,1302,4334)$ and maintenance of normal (fasting) blood concentrations of triglycerides (ID 673, 4334) pursuant 
to Article 13(1) of Regulation (EC) No1924/2006. EFSA Official Journal 4:2043

Giannakourou MC, Koutsoumanis K, Nychas GJE, Taoukis PS, 2005. Field evaluation of the application of time temperature integrators for monitoring fish quality in the chill chain. Int J Food Microbiol 102:323-36.

ISO,1993. Sensory analysis. General guidance for the selection, training and monitoring of assessors. Part 1: Selected assessors. ISO Norm 8586$1: 1993$. International Organization for Standardization, Geneva, Switzerland.

ISO, 2003. Sensory Analysis. Methodology. General Guidance for Establishing a Sensory Profile. ISO Norm 13299:2003 International Organization for Standardization, Geneva, Switzerland.

ISO, 2007. Microbiologia di alimenti e mangimi per animali. Requisiti generali e guida per le analisi microbiologiche. Norm UNI EN ISO 7218:2007. International Organization for Standardization, Geneva, Switzerland.

ISO 8586-2:2008 (Sensory analysis General guidance for the selection, training and monitoring of assessors Part 2: Experts. ISO Norm 85862:2008. International Organization for Standardization, Geneva, Switzerland.

Jedermann R, Ruiz-Garcia L, Lang W, 2009. Spatial temperature profiling by semi-passive RFID loggers for perishable food transportation. Comput Electronics Agricult 65:145-54.

Kloss L, Meyer JD, Graeve L, Vetter W, 2015. Sodium intake and its reduction by food reformulation in the European Union: A review. NFS J 1:9-19.

Kopicova Z, Vavreinova S, 2007. Occurrence of squalene and cholesterol in various species of Czech freshwater fish. Czech J Food Sci 25:195-201,

Lindström M, Kiviniemi K, Korkeala H, 2006. Hazard and control of group II (non-proteolytic) Clostridium botulinum in modern food processing. Int $\mathrm{J}$ Food Microbiol 108:92-104

Lobo CMDO, Torrezan R, de Furtado ÂAL, Antoniassi R, Freitas DDGC, de Freitas SC, Penteado AL, de Oliveira CS, Conte CAJ, Mársico ET, 2015. Development and nutritional and sensory evaluation of cachapinta (Pseudoplatystoma sp) pâté. Food Sci Nutr 3:10-6.
Margosch D, Ehrmann MA, Buckow R, Heinz V, Vogel RF, Gänzle MG, 2006. High-pressure-mediated survival of Clostridium botulinum and Bacillus amyloliquefaciens endospores at high temperature. Appl Environ Microbiol 72:3476-81.

Minozzo MG, Waszczynskyj N, Beirao LH, 2004. Caracterısticas fisico-quimicas do pâté de Tilapia do Nilo (Oreochromis niloticus) comparado a produtos similares comerciais. Alimentos e Nutricao 15:101-5.

Natali M, 2002. I pesci del lago Trasimeno. Tipolitografica Grifo, Perugia.

Özogul Y, Özogul F, Alagoz S, 2007. Fatty acid profiles and fat contents of commercially important seawater and freshwater fish species of Turkey: A comparative study. Food Chem 103:217-23.

Özogul Y, Ozogul F, Kuley E, 2010. Effects of combining of smoking and marinating on the shelf life of anchovy stored at 4 C. Food Sci Biotechnol 19:69-75.

Papp ZS, Kerepeczki E, Peckàr F, Gàl D, 2007. Natural origins of off-flavours in fish related to feeding habits. Water Sci Technol 55:301-9.

Pecorelli I, Branciari R, Ortenzi R, Ciriaci M, Checcarelli S, Roila R, Capotorti A, Spaccini G, Valiani A, 2018. Evaluation of the concentration factor of aflatoxin M1 in a semi-hard Pecorino cheese obtained from naturally contaminated milk. Food Control 85:194-8.

Ranucci D, Miraglia D, Branciari R, Morganti G, Roila R, Zhou K, Jiang H, Braconi P, 2018. Frankfurters made with pork meat, emmer wheat (Triticum dicoccum Schübler) and almonds nut (Prunus dulcis Mill.): evaluation during storage of a novel food from an ancient recipe. Meat Sci 145:440-6.

Reddy NR, Tetzloff RC, Skinner GE, 2010. Effect of media, additives, and incubation conditions on the recovery of high pressure and heat-injured Clostridium botulinum spores. Food Microbiol 27:613-7.

Schwingshackl L, Hoffmann G, 2014. Monounsaturated fatty acids, olive oil and health status: a systematic review and meta-analysis of cohort studies. Lipids Health Dis 13:154.

Shaviklo GR, Arason S, Thorkelsson G, Sveinsdottir K, Martinsdottir E, 2010. Sensory attributes of haddock balls affected by added fish protein isolate and frozen storage. J Sens Stud 25:316-
31.

Silva FV, Gibbs PA, 2010. Non-proteolytic Clostridium botulinum spores in lowacid cold-distributed foods and design of pasteurization processes. Trends Food Sci Technol 21:95-105.

Steffens W, 1997. Effects of variation in essential fatty acids in fish feeds on nutritive value of freshwater fish for humans. Aquaculture 151:97-119.

Tocher DR, 2003. Metabolism and functions of lipids and fatty acids in teleostei fish. Rev Fish Sci 11:107-84.

Turchini GM, Mentasti T, Caprino F, Panseri S, Moretti VM, Valfrè F, 2004. Effects of dietary lipid sources on flavour volatile compounds of brown trout (Salmo trutta L.) fillet. J Appl Ichthyol 20:71-5.

US-FDA, 2001. Evaluation and Definition of Potentially Hazardous Foods. Report of the Institute of Food Technologists for the Food and Drug Administration of the United States Department of Health and Human Services.

Van Asselt ED, Zwietering MH, 2006. A systematic approach to determine global thermal inactivation parameters for various food pathogens. Int $\mathrm{J}$ Food Microbiol 107:73-82.

van der Horst K, Brunner TA, Siegrist M, 2011. Fast food and take-away food consumption are associated with different lifestyle characteristics. J Hum Nutr Diet 24:596-602.

Varga D, Sàndor Z, Hancz, C, Csengeri I, Jeney Z, Papp Z, 2015. Off-flavour compounds in common carp (Cyprinus Carpio L.) flesh in context of type of fish type of fish pond. Acta Alim 44:311-5

Vasconi M, Caprino F, Bellagamba F, Busetto ML, Bernardi C, Puzzi C, Moretti VM, 2015. Fatty acid composition of freshwater wild fish in subalpine lakes: a comparative study. Lipids 50:283-302.

Venugopal V, Shahidi F, Lee TC, 1995. Value-added products from underutilized fish species. Crit Rev Food Sci Nutr 35:431-53.

Visioli F, Galli C, 1998. The effect of minor constituents of olive oil on cardiovascular disease: new findings. Nutr Rev 56:142-7. 